\title{
Roots and Seeds: Finding Our Place in the Social Practice Nexus That Is Quantitative Literacy
}

H. L. Vacher

University of South Florida, vacher@usf.edu

Nathan D. Grawe

Carleton College, ngrawe@carleton.edu

Follow this and additional works at: https://digitalcommons.usf.edu/numeracy

Part of the Communication Commons, Library and Information Science Commons, Mathematics Commons, Scholarship of Teaching and Learning Commons, and the Science and Mathematics Education Commons

\section{Recommended Citation}

Vacher, H. L., and Nathan D. Grawe. "Roots and Seeds: Finding Our Place in the Social Practice Nexus That Is Quantitative Literacy." Numeracy 12, Iss. 2 (2019): Article 1. DOI: https://doi.org/10.5038/

1936-4660.12.2.1 


\title{
Roots and Seeds: Finding Our Place in the Social Practice Nexus That Is Quantitative Literacy
}

\begin{abstract}
The purpose of our new Roots and Seeds feature is to provide an open-access space to archive first-hand accounts of QL activities that have preceded our journal (2008). The first two contributions in the collection appeared last issue: Linda Sons on the making of what has come to be known as the 1994 Sons Report (Mathematics Association of America), and Dorothy Wallace on her path to the Quantitative Literacy Design Team for Mathematics and Democracy (2001), and the questions that bedeviled them then - and us now. In this issue, we get Rick Gillman's account of how the committee that produced the Sons Report transitioned into an intra-MAA special interest group, the SIGMAA-QL, which led to a QL special publication, MAA Math Notes \#70 (2004). These three histories, together with the From the Author piece in this issue by Tunstall, Piercey and Karaali on the just-published Math Notes (\#88) (sequel to \#70) paint a picture already of the history of QL as a nexus of social practices involving people, institutions, societies, committees, publications, and more. So far, two major threads are evident: the MAA thread and the NCED thread (National Council on Education and the Disciplines); the NCED thread, which includes Mathematics and Democracy and the National Numeracy Network, is a legacy of non-mathematician Robert Orrill.
\end{abstract}

We hope and expect that the Roots and Seeds collection will speak to the notion of communities within our community, and numeracies within what we and Numeracy call "numeracy." In that vein, we define Numeracy's target community as "people who care about QL," and for that community we muse on a Venn model of three intersecting sets: (1) mathematicians, (2) inside the U.S., and (3) publish in Numeracy, and we resolve to expand our numbers in all eight subsets of the target community.

We close by noting that this issue also contains the second installment of a theme collection on social justice. That is our third such collection - the others being financial literacy (2013) and assessment (2015) - which reminds us, of course, of the great potential of thematic threads through our QL nexus. So far, the Roots and Seeds have all been on organizational threads. We have only just begun.

\section{Keywords}

Quantitative literacy, numeracy, numeracies, social practice, new literacies, Venn model, Mathematics Association of America, National Numeracy Network, National Council on Education and the Disciplines

\section{Creative Commons License}

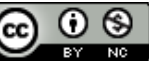

This work is licensed under a Creative Commons Attribution-Noncommercial 4.0 License

\section{Cover Page Footnote}

Len Vacher is a professor of geology in the School of Geosciences, University of South Florida, Tampa, and a senior editor of Numeracy.

Nathan D. Grawe is a professor of economics at Carleton College and the executive editor of Numeracy. 
Long-time readers may have noted a new category of papers in this volume, beginning with the last issue: "Roots and Seeds." This class of works intends to collect first-hand accounts of quantitative literacy (QL) activities that have preceded our journal. This is not our first foray into gathering our discipline's history. For example, the paper by Madison and Steen (2008) in our inaugural issue records the establishment of the National Numeracy Network and Numeracy. More recently, we have published bibliographies of papers in Numeracy (2008-2015) citing papers by and in volumes edited by American numeracy's two most prolific thought leaders, Lynn Arthur Steen ${ }^{1}$ (Vacher 2016) and Bernard L. Madison ${ }^{2}$ (Grawe and Vacher 2017). Now, by codifying a new space within Numeracy for publishing witnessed histories, we intend to foster a more systematic archive of our collective past to facilitate the passing of the baton from one academic generation to the next.

History is a powerful thing - in numerous and various ways. Of course, a history of numeracy scholarship will tell us where we've been and thus how far we've come. But, additionally, with some reflection, it will show how our past contains nuggets that become keys to solving new problems and advancing new agendas. Thus by providing a repository for stories that, individually and collectively, show how germs became ideas became pilot projects became initiatives, we hope to nurture and inspire continued developments in our community's collective work.

Our first three contributions to the Roots and Seeds collection capture the notion of these continuities well. In the last issue, Numeracy contributing editor Dorothy Wallace (2019) provides insight into how the Quantitative Literacy Design Team led to the foundational ideas for Mathematics and Democracy (Steen 2001a), which in turn prompted the creation of the National Numeracy Network, which begat Numeracy. Along the way in her Roots and Seeds paper, Wallace notes an intersection with the Sons Report (Sons 1994), the topic of Linda Sons' Roots and Seeds paper in the same issue (Sons 2019).

Sons (2019) describes the critical years between 1989 and 1994 in which the Mathematical Association of America (MAA) wrestled with the organization's responsibility to QL. While much has changed in the ensuing decades, the contributions of the Sons Report remain fresh. Few who have designed QL initiatives on their campuses are unfamiliar with the five goals of a "quantitatively literate college graduate" laid out in the 2004 report and relisted in Sons (2019, Table 2).

\footnotetext{
${ }^{1}$ President of the Mathematical Association of America (MAA), 1985-1986.

${ }^{2}$ Numerous leadership and committee roles in MAA, especially in the area of assessment: director of MAA's program on placement testing; NSF grants to MAA, including Supporting Assessment in Undergraduate Mathematics (DUE \#0127694: 2002-2006).
} 
As readers familiar with the history of the MAA and QL know, one offshoot of the Sons Report was a new special interest group within the MAA: the SIGMAA-QL. This is where Rick Gillman (2019), the founding Past President of the SIGMA-QL, takes up the MAA-QL thread in the current issue. He shares how the MAA added QL to its CUPM (Committee on Undergraduate Programs in Mathematics) Curriculum Guidelines (Barker et al. 2004) and created SIGMAAQL in 2004 as a new version of the QL Subcommittee of CUPM, the subcommittee that Linda Sons chaired that produced the 1994 report. In addition, he provides insights into the early work of the special interest group including the writing of MAA Notes \#70 (Fig. 1), which provided early examples of QL courses and programs in a variety of institutional contexts.

Fortuitously the current issue of Numeracy also features papers introducing MAA Notes \#88 (Tunstall et al. 2019), the much-anticipated sequel to \#70. We note that comparing the tables of contents included as appendices in the respective Roots and Seeds (Gillman 2019, this issue) and From the Authors (Tunstall et al. 2019, this issue) papers makes for interesting browsing. Comparing the two sets of contents of these successive QL MAA Notes volumes published 13 years apart underscores the points we noted above about history. Not only does history show where we have been and

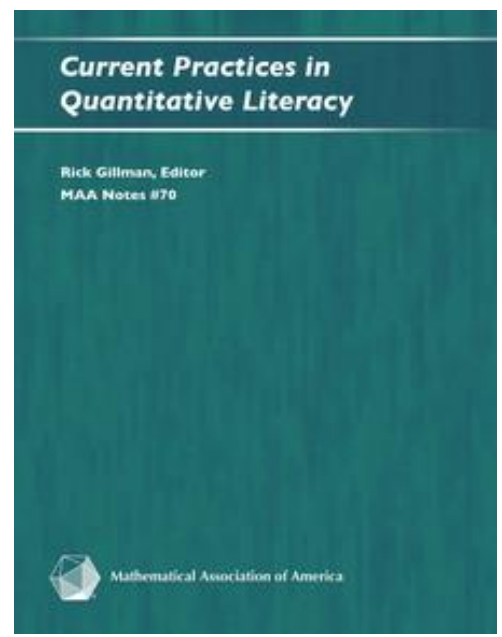

Figure 1. Gillman (2006).

how far we have come; it shows how some kernels of QL ideas have flourished into full-blown courses and institutional initiatives. Moreover, readers of our first three Roots and Seeds pieces will notice that all three authors note connections between the dilemmas faced by early QL leaders and the challenges that confound us today. In a very real sense, then, while much progress has been made, Steen's (2001b, 10) assessment still rings true: "Despite years of study and life experience immersed in quantitative data, many educated adults remain functionally innumerate." And thus we can draw on insights and experiences from the past to inform the present.

Careful study of the past also reveals that history is not a single thread but rather a nexus of stories. We should expect there to be more to the story of QL than the MAA thread. In that regard, we note what Dorothy Wallace $(2019,2)$ said in her Roots and Seeds piece about non-mathematician Bob Orrill.

Toward the end of the Mathematics Across the Curriculum project at Dartmouth, I became involved with the Quantitative Literacy Design Team - a group of individuals, 
led by Robert Orrill, which were brought together several times over a period of years to consider strategies that might improve the quantitative literacy of students at the high school and college levels.

Meanwhile, in Math Notes \#88, Susan Ganter (2019, ix) said much the same thing in her Forward for the volume:

... Lynn Steen and Bob Orrill asked me to participate in a design team they were forming as part of the work of the National Council on Education and the Disciplines (NCED). The purpose of the design team was to discuss and develop a working definition for QL, in light of Steen and Orrill's recent work in Why Numbers Count (Steen 1997).

In Chapter 4 of the Math Notes \#88 volume, Madison (2019, 41-42) gives some detail about the NCED, Why Numbers Count (Fig. 2), and Mathematics and Democracy (Fig. 3):

In 1997, the College Board, under the guidance of Robert Orrill and Lynn Steen, published Why Numbers Count, the first of what was to be four volumes in the most recent initiative concerning QL. Subsequent to the publication of Why Numbers Count, with support from the Pew Charitable Trusts, Orrill founded and directed the NCED whose goal was to promote discussion about core literacies at the transition from secondary to postsecondary education. Its first initiative [was] Mathematics and Democracy.... As of now, the NCED is inactive but its role in getting the current initiative on QL underway deserves notice. One of the vestiges of the NCED's work is the principal QL/QR supporting organization, the NNN.

Susan Ganter was the founding Director of the NNN during its initial, NCED stage (2001-2004) when it was a federation of quantitative literacy centers. Bernie Madison took the reigns as the first president when it became a membership 501(c)(3) organization in 2004 (see also Madison and Steen 2008).

Thus (Fig. 4), we have a second, NCED thread, from WNC (Why Numbers Count: Quantitative Literacy for Tomorrow's America), to $M \& D$ (Mathematics and

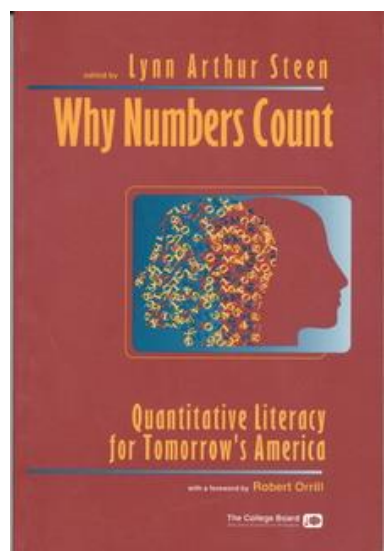

Figure 2. Steen (1997).

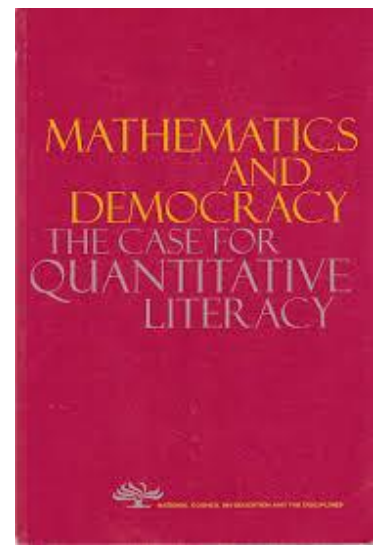

Figure 3. Steen (2001a). 
Democracy: The Case for Quantitative Literacy, to the NNN (the National Numeracy Network), to Numeracy (Fig. 4) (Steen and Madison 2011). In a very real way, this NCED thread can be viewed as a legacy of Bob Orrill.

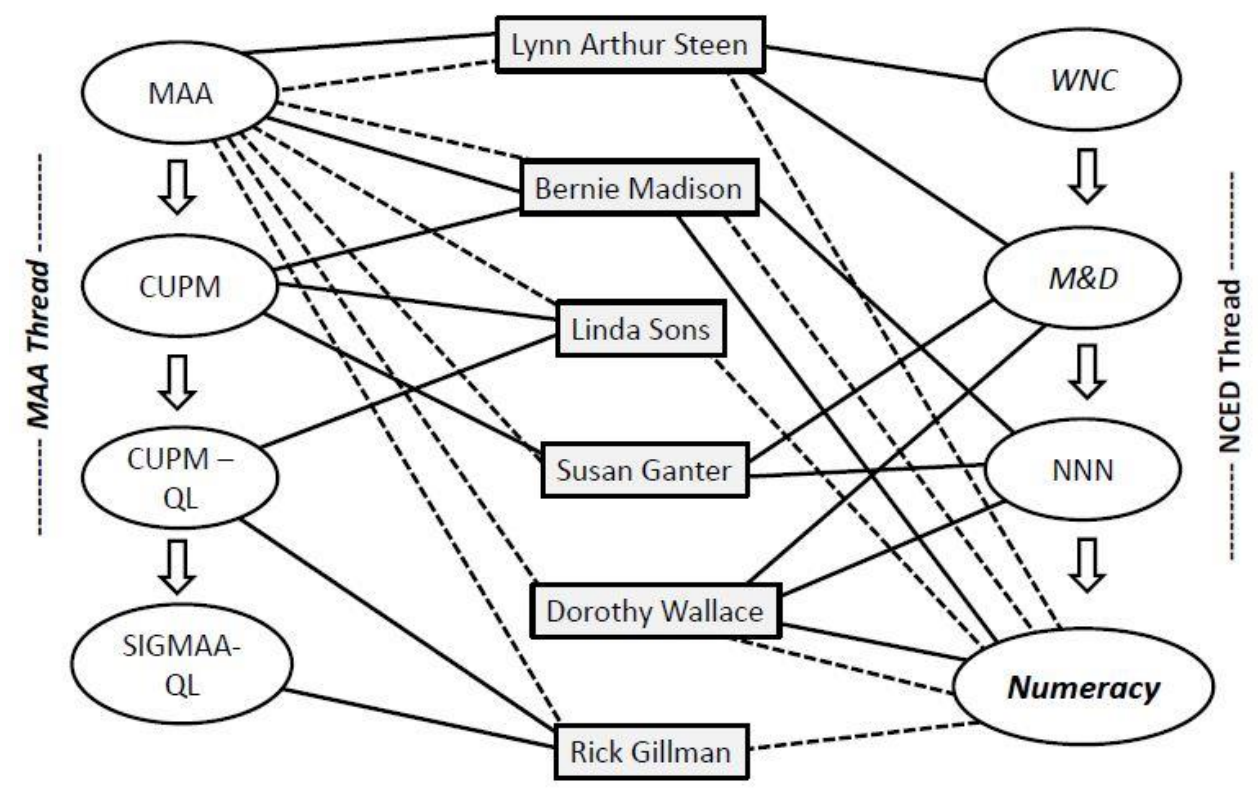

Figure 4. Two threads in the American QL story. Solid-line links denote connections referred to in this editorial. Dashed-line links denote active participation (e.g., meetings etc. for MAA, "published in" for Numeracy).

As shown in Figure 4, our three Roots and Seeds papers, in combination with the just-published MAA Notes \#88, already show that QL histories are interconnected. Just as a plant has many roots, so too does the QL movement. Moreover, the roots become intertwined and thereby create a strong base of support to sustain a broader mission.

The message of Figure 4 is that the history of QL, when fleshed out, will be seen as a nexus of people, institutions, societies, publications, and no doubt more. So far, with just these two threads (MAA and NCED), we have included six mathematicians, three membership organizations, two society committees, two seminal edited volumes, and one enthusiastic journal. Stop and think about it. It's only the start of a bigger picture.

Zooming out from Figure 4, we are beginning to see that QL history is a nexus of social practices. This view is in keeping with the thinking of the "new literacies" social-practice concept of numeracy. For example, Fisher (2019) and Craig et al. (2019) in the first two chapters of the new Math Notes \#88 build on the seminal work of James Gee in the U.S. (e.g., Gee 2015) and the late Brian 
Street in the U.K. (e.g., Street et al. 2005) and aim to "reconceptualize quantitative literacy as a social practice" (Craig et al. 2019, 16). As argued by (Fisher 2019, 4) (see also Tunstall et al. 2019, this issue):

all forms of literacy involve a representational medium that is shared by different social groups, each with its own unique practices surrounding that medium. As such, literacy is an inherently social phenomenon, and we cannot divorce the study of QL from the social contexts in which it is realized.

This concept has been applied and elaborated in at least six papers in Numeracy (Frith 2012; Frith and Lloyd 2016; Karaali et al. 2016; Frith and Prince 2018; Oughton 2018; Craig and Guzmán 2018), all of which cite one or more of the works of Gee or Street.

Why is the notion of QL as social practice important to our Roots and Seeds project? Community, communities, and communication are all central to the whole notion of quantitative literacy, as shown by a new definition proffered by Fisher $(2019,4)$ :

Quantitative literacy is the facility to participate in the intersecting quantitative practices of many different communities (each with its own patterns of discourse).

In the spirit of that definition then, who are we? What is our community? Can we identify constituent sub-communities?

We in Numeracy operate on the assumption that our community is the people we aim to serve, namely people who care about quantitative literacy. Those people are shown conceptually in the four-set Venn diagram of Figure 5a, where the universal set is "people." They are also shown on the three-set Venn diagram of Figure $5 \mathrm{~b}$ as the universal set. Our community is the shaded large ellipse in Figure 5a and the shaded rectangle in Figure 5b. It is set $A$ in both diagrams.

The Venn diagrams also show three other sets: mathematicians; people in the U.S.; and people who publish in Numeracy. They are sets $B, C$, and $D$, respectively. These other sets are the three other large ellipses in Figure 5a and the three circles of the more familiar three-circle Venn diagram of Figure $5 \mathrm{~b}$. The eight subsets of set $A$ are as follows using the set labels of Figure $5 b$ (prefix those with $A$ to produce the set labels of Fig. 5a).

- $B C D$ : mathematicians in the U.S. who publish in Numeracy

- $\quad B C \bar{D}$ : mathematicians in the U.S. who do not publish in Numeracy

- $\quad B \bar{C} D$ : mathematicians outside the U.S. who publish in Numeracy

- $\bar{B} C D$ : non-mathematicians in the U.S. who publish in Numeracy

- $\bar{B} C \bar{D}$ : non-mathematicians in the U.S. who do not publish in Numeracy

- $\quad B \bar{C} \bar{D}$ : mathematicians outside the U.S. who do not publish in Numeracy

- $\bar{B} \bar{C} D$ : non-mathematicians outside the U.S. who publish in Numeracy

- $\bar{B} \bar{C} \bar{D}$ : non-mathematicians outside the U.S. who do not publish in Numeracy 
For the obvious reason of low-hanging fruit, our solicitations of Roots and Seeds papers published thus far have focused on the $A B C$ intersection (mathematicians in the U.S. who care about QL). That sub-community of our community (set $A$ ) is obviously substantial; for example, it includes the three editors and likely all the authors of Math Notes \#88. Many of those authors are in the $A B C D$ subset of $A B C$, having already published in Numeracy. (Two of our first three Roots and Seeds authors moved from the $A B C \bar{D}$ subset to the $A B C D$ subset by publishing their Roots and Seeds paper.) It is safe to say, we believe, that the $A B C$ subcommunity is reasonably homogeneous with respect to its social practices and ability to communicate within its group. But what about the $B$-ellipse boundary (between mathematicians and non-mathematicians) or the $C$-ellipse boundary (between in- and outside-U.S.). As members of $A \bar{B}$ ourselves, professionally, and having worked with Numeracy authors from $A \bar{C}$, we both know that both of those graphical boundaries mark borders between subcommunities in terms of social practices, linguistics, and understandings within $A$. Moreover, we can attest that our own particular subset, $A \bar{B} C D$ (nonmathematicians inside the U.S. who care about QL and publish in Numeracy), is anything but homogeneous, given the disparate literacies of our home disciplinary fields; $A \bar{B} C D$ is itself a nest of sub-communities. 
Referring back to Figure 4, we should note that the explored threads above have emphasized social practices in terms of organizations and their products. Surely, there are other types of threads through the history of QL. Probably most obvious are thematic, topical threads - "thematic" in the same sense as Numeracy's Theme Collections. So far, we have had three theme collections: Financial Literacy, with eight papers in 2013 (vol. 6, issue 2); Assessment, with five papers in 2015 (vol. 8, issue 1); and Social Justice in 2019, with four papers last issue (vol. 12, issue 1), and four more this issue (vol. 12, issue 2). All three are thematic topics in Numeracy, as one can see by using the search tool on Numeracy's home page (6/30/2019): "financial literacy" finds 39 out of the journal's 247 papers; "assessment" finds 187/247; and "social justice," 27/247. Of note, too: compare the social justice theme collection editors (Kira Hamman, Victor Piercey, Luke Tunstall) with the Math Notes \#88 editors (Tunstall, Gizem Karaali, Piercey); again a nexus of intertwining thematic, organizational, and other threads among the networked nodes in our community is evident.

As the Roots and Seeds collection accumulates witnessed stories and the witness's reflections on them, the collection in aggregate will be both filling in and zooming out on the nexus of people, institutions, disciplines, themes, places, and academic and nonacademic cultures that come into play in the various stories and threads of QL. The goal is to be better able to communicate with and learn from people in other parts of the great heterogeneous community of people who care about quantitative literacy.

If any of you have ideas for a Roots and Seeds contribution, we encourage you to contact Senior Editor Len Vacher or Senior Editor Bernie Madison.

\section{References}

Barker, William, David Bressoud, Susanna Epp, Susan Ganter, Bill Haver, and Harriet Pollatsek (chair). 2004. Undergraduate Programs and Courses in the Mathematical Sciences: CUPM Curriculum Guide 2004. Washington, DC: Mathematical Association of America.

Craig, Jeffrey and Lynette Guzmán. 2018. "Six Propositions of a Social Theory of Numeracy: Interpreting an Influential Theory of Literacy." Numeracy 11(2):

Article 2. https://doi.org/10.5038/1936-4660.11.2.2

Craig, Jeffrey, Rohit Mehta, and James P. Howard II. 2019. "Quantitative Literacy to New Quantitative Literacies." In Shifting Contexts, Stable Core: Advancing Quantitative Literacy in Higher Education, edited by Luke Tunstall, Gizem Karaali, and Victor Piercey, 15-25. Washington, DC: Mathematical Association of America.

Fisher, Forest. 2019. "What Do We Mean by Quantitative Literacy?" In Shifting Contexts, Stable Core: Advancing Quantitative Literacy in Higher Education, 
edited by Luke Tunstall, Gizem Karaali, and Victor Piercey, 3-14.

Washington, DC: Mathematical Association of America.

Frith, Vera. 2012. "Quantitative Literacy Interventions at University of Cape Town: Effects of Separation from Academic Disciplines." Numeracy 5(1): Article 3. https://doi.org/10.5038/1936-4660.5.1.3

Frith, Vera and Pam Lloyd. 2016. "Investigating Proportional Reasoning in a University Quantitative Literacy Course.” Numeracy 9(1): Article 3. https://doi.org/10.5038/1936-4660.9.1.3

Frith, Vera and Robert N. Prince. 2018. "The National Benchmark Quantitative Literacy Test for Applicants to South African Higher Education." Numeracy 11(2): Article 3. https://doi.org/10.5038/1936-4660.11.2.3

Ganter, Susan L. 2019. "Considering Quantitative Literacy in the Context of Dewey, Data, and the Ever-shifting Landscape of a Democratic Society." In Shifting Contexts, Stable Core: Advancing Quantitative Literacy in Higher Education, edited by Luke Tunstall, Gizem Karaali, and Victor Piercey, ixxi. Washington, DC: Mathematical Association of America.

Gee, James. 2015. Social Linguistics and Literacies: Ideology in Discourses. 5th ed. New York, NY: Routledge.

Gillman, Rick, ed. 2006 . Current Practices in Quantitative Literacy. MAA Notes \#70. Washington DC: Mathematical Association of America.

Gillman, Rick. 2019. "Quantitative Literacy and the Mathematical Association of America in the 2000's: QL Subcommittee of CUPM , SIGMAA QL, and MAA Notes \#70.” Numeracy 12(2): Article 12. https://doi.org/10.5038/1936-4660.12.2.12

Grawe, Nathan D. and H. L. Vacher. (2017). "A Madison-Numeracy Citation Index (2008-2015): Implementing a Vision for a Quantitatively Literate World." Numeracy 10(1): Article 1. https://doi.org/10.5038/1936-4660.10.1.1

Karaali, Gizem, Edwin H. Villafane Hernandez, and Jeremy A. Taylor. 2016. "What's in a Name? A Critical Review of Definitions of Quantitative Literacy, Numeracy, and Quantitative Reasoning." Numeracy 9(1): Article 2. https://doi.org/10.5038/1936-4660.9.1.2

Madison, Bernard L. 2019. "Quantitative Literacy: An Orphan No Longer." In Shifting Contexts, Stable Core: Advancing Quantitative Literacy in Higher Education, edited by Luke Tunstall, Gizem Karaali, and Victor Piercey, 3746. Washington, DC: Mathematical Association of America.

Madison, Bernard L., and Lynn A. Steen. 2008. "Evolution of Numeracy and the National Numeracy Network." Numeracy 1(1): Article 2. DOI: http://dx.doi.org/10.5038/1936-4660.1.1.2

Millard, Rupert. 2009. "Venn's Four Ellipse Construction." Wikipedia Commons. https://commons.wikimedia.org/wiki/File:Venn\%27s_four_ellipse_constructi 
on.svg. CCA SA-3.0 license. https://creativecommons.org/licenses/by$\underline{\mathrm{sa} / 3.0 / \text { legalcode }}$

Oughton, Helen M. 2018. "Disrupting Dominant Discourses: A (Re)Introduction to Social Practice Theories of Adult Numeracy." Numeracy 11(1): Article 2. https://doi.org/10.5038/1936-4660.11.1.2

Sons, Linda R., ed. 1994. Quantitative Reasoning for College Students: A Complement to the Standards. Washington, D C: Mathematical Association of America. https://www.maa.org/programs/faculty-anddepartments/curriculum-department-guidelinesrecommendations/quantitative-literacy/quantitative-reasoning-collegegraduates

Sons, Linda R. 2019. "The Sons Report (1989-1994, Mathematics Association of America): The Way It Was.” Numeracy 12(1): Article 12. https://doi.org/10.5038/1936-4660.12.1.12

Steen, Lynn Arthur. 1997. Why Numbers Count: Quantitative Literacy for Tomorrow's America. New York, NY: College Entrance Examination Board

Steen, Lynn Arthur, ed. 2001a. Mathematics and Democracy: The Case for Quantitative Literacy. Princeton NJ: The National Council on Education and the Disciplines.

Steen, Lynn Arthur. 2001b. "Mathematics and numeracy: Two literacies, one language." The Mathematics Educator 6(1): 10-16.

Steen, Lynn Arthur and Bernard L. Madison. 2011. "Reflections on the Tenth Anniversary of Mathematics and Democracy." Numeracy 4(1): Article 1. https://doi.org/10.5038/1936-4660.4.1.

Street, B, D. Baker, and A. Tomlin. 2005. Navigating Numeracies: Home/School Numeracy Practices. Dordrecht: Kluwer.

Tunstall, Luke, Gizem Karaali, and Victor Piercey, eds. 2019. Shifting Contexts, Stable Core: Advancing Quantitative Literacy in Higher Education. Washington DC: Mathematical Association of America.

Tunstall, Samuel L., Gizem Karaali, and Victor Piercy. 2019. "Introducing MAA Notes \#88: Shifting Contexts, Stable Core: Advancing Quantitative Literacy in Higher Education." Numeracy 12(2): Article 13. https://doi.org/10.5038/1936-4660.12.2.13

Vacher, H. L. 2016. "Remembering Lynn Steen: A Steen-Numeracy Citation Index (2008-2015)." Numeracy 9(1): Article 1. https://doi.org/10.5038/19364660.9.1.1

Wallace, Dorothy. 2019. "Three Formative Questions in the Quantitative Literacy Movement." Numeracy 12(1): Article 13. https://doi.org/10.5038/1936$\underline{4660.12 .1 .13}$ 